\title{
Do Demographic Profiles of Listed and Unlisted Households Differ? Results of a Nationwide Telephone Survey
}

\author{
Renee N. Carey, ${ }^{1,2}$ Alison Reid, ${ }^{1}$ Susan Peters, ${ }^{1}$ and Lin Fritschi ${ }^{1}$ \\ ${ }^{1}$ Harry Perkins Institute of Medical Research, The University of Western Australia, Perth, WA 6009, Australia \\ ${ }^{2}$ Sir Charles Gairdner Hospital, B Block, Hospital Avenue, Nedlands, WA 6009, Australia \\ Correspondence should be addressed to Lin Fritschi; lin.fritschi@uwa.edu.au
}

Received 15 September 2013; Accepted 14 February 2014; Published 18 March 2014

Academic Editor: Susana Sans Menendez

Copyright (c) 2014 Renee N. Carey et al. This is an open access article distributed under the Creative Commons Attribution License, which permits unrestricted use, distribution, and reproduction in any medium, provided the original work is properly cited.

\begin{abstract}
A growing number of households are not reachable through traditional directory-based samples, which can have important implications for the representativeness of telephone surveys. The current study aims to investigate the demographic differences between households which have their telephone numbers listed or not listed in the Australian White Pages telephone directory. A total of 5,023 eligible Australian residents who were currently in paid employment participated in this study. Each respondent's telephone number was individually matched to the residential White Pages to determine its listed status, and demographic variables were compared between those with a listed and unlisted telephone number. Those with an unlisted number were significantly more likely to be younger, to have been born in a country outside of Australia, and to live in a lower socioeconomic area than those who were listed in the White Pages. These demographic differences should be considered when undertaking telephone surveys using a White Pages sample.
\end{abstract}

\section{Introduction}

Those wishing to gather information from large groups of individuals have long turned to the telephone as a means of reaching a representative sample of the population. Telephone surveys have the advantage of cost efficiency and timeliness $[1,2]$ and generally achieve higher response rates than mail surveys [3]. The traditional sampling frame for such surveys is the telephone directory. However, although approximately $85 \%$ of Australians have a fixed line home telephone [4], a growing number of households are not reachable through traditional directory-based samples, with an estimated 18\% of Queensland households in 2004 [5] and $31 \%$ of South Australian households in 2008 not having a fixed line or mobile telephone number listed in the White Pages telephone directory [1]. This may largely be due to the fact that many people choose to only have a mobile telephone, and these numbers are only listed in the Australian directory if the owner requests it.

Excluding unlisted numbers from the sampling frame can have important implications for the representativeness of the final sample [6] and may result in certain subgroups of the population being omitted [7]. For example, people living in unlisted households have generally been reported to be younger, to live in metropolitan areas, and to reside in lower socioeconomic status areas than those in households with a telephone directory listing $[1,6,8,9]$. In addition, studies conducted in South Australia and New South Wales have shown that those with an unlisted residential telephone number are more likely to have been born outside of Australia and to speak a language other than English $[1,10]$. Important health and lifestyle differences have also been found, with those living in unlisted households more likely to be current smokers and less likely to report high blood pressure or cholesterol levels [11].

The literature is, however, less consistent with regard to educational attainment. A South Australian study, for example, found that those in unlisted households were more likely to have achieved a higher educational level than those living in listed households [1], while in New South Wales no significant difference between listed and unlisted 
households was observed in terms of educational attainment [10]. International studies have also reported inconsistent results in this regard, with unlisted Chicago residents being more likely to have a lower educational level [6] and those living in unlisted households in Germany being more likely to have received a tertiary education than those with a listed number [9].

It is possible that differences in the characteristics of listed and unlisted households vary by country, and so local information is vital in order to ensure that researchers are not obtaining a biased sample. Although previous Australian studies have been published in this area $[1,8,10,11]$, these have been limited to two states. One aim of the current study is therefore to investigate whether the proportion of listed and unlisted households differs between states, in an attempt to explore whether these earlier findings may be applicable to Australia as a whole. In addition, this study aims to investigate differences in terms of other demographic variables, including age, country of birth, and socioeconomic status, and to further explore the role of educational level in light of past inconsistent findings.

\section{Materials and Methods}

This study was conducted as part of the Australian Work Exposures Study (AWES), a nationwide telephone survey investigating the prevalence of occupational exposure to carcinogens in Australia. Ethics approval for this study was received from the University of Western Australia's Human Research Ethics Committee.

The sample for this study was randomly selected from a list of approximately 6 million Australian households supplied by a commercial survey sampling firm. This list consisted of household telephone numbers and address details which had been sourced from various public domain data sources. Both landline and mobile telephone numbers were available but we excluded mobile numbers from this paper because only $5 \%$ of the numbers were mobiles; mobile numbers tend to be an individual rather than a household sampling frame, and there are different processes for listing mobiles in the directory. Each telephone number was individually matched to the residential White Pages to determine its listed status. Where a number could not be matched, it was assigned to the unlisted group.

Telephone interviews were conducted with Australian residents aged between 18 and 65 who were currently in paid employment. The sample was stratified to approximate the distribution of the Australian work force by state and territory according to the Australian Bureau of Statistics Labour Force Statistics from March 2011 [12]. In addition, an attempt was made to recruit respondents in the gender ratio of two males to every female via the use of a modified interview request, whereby the interviewer asked to speak to a male in six out of seven telephone calls. If there was more than one person in the household of the required gender, the interviewer asked for the person who was next to have a birthday. Up to ten call attempts to each household were made before attempts at contact were terminated.

All interviews were conducted by trained interviewers, who gave a brief description of the study and obtained oral informed consent from the respondent. Demographic information collected from each respondent included age, gender, postcode of residence, country of birth, length of residence in Australia (if relevant), language most commonly spoken at home, and education level. Socioeconomic status (SES) and remoteness were determined by applying the Australian Bureau of Statistics Socio-Economic Indexes for Areas Index of Relative Socio-Economic Disadvantage (SEIFA IRSD; [13]) and Australian Standard Geographical Classification Accessibility/Remoteness Index of Australia (ARIA+; [14]) to each postcode of residence. The IRSD scores were grouped into quintiles for analysis, with the lowest quintile comprising the most disadvantaged areas.

Odds ratios (ORs) and 95\% confidence intervals (CIs) were estimated using logistic regression in order to explore which demographic variables were associated with having an unlisted telephone number. Univariate analyses were carried out for each variable and then all variables were entered simultaneously to adjust for confounding. All analyses were conducted using Stata version 12 [15].

\section{Results}

Of the 6,895 eligible households contacted, interviews were conducted with 5,023 respondents, resulting in a cooperation rate (completed interviews/eligible households) of $72.8 \%$. After omitting mobile telephone numbers we were left with a sample size of 805 unlisted and 3972 listed fixed line numbers. When the demographic characteristics of listed and unlisted households were compared, respondents from unlisted households were significantly more likely to be aged under 35 and less likely to be aged over 50 . They were also more likely to have been born in a country other than Australia and to live in a major city (Table 1). Those with an unlisted number were also more likely to live in New South Wales and Western Australia as compared to Victoria.

In addition, although socioeconomic status was not associated with having an unlisted telephone number in the unadjusted analysis, when adjusted for all other demographic variables in the model, the relationship between having an unlisted number and living in a low socioeconomic status area became statistically significant. Similar results emerged for state, whereby living in Queensland was associated with having an unlisted telephone number in the adjusted analysis only.

In an attempt to further explore the role of country of birth, length of residence in Australia was also investigated. In multivariate analyses, adjusting for age, those residing in Australia for less than 10 years $(n=150)$ were 2.48 times $(95 \%$ CI 1.66-3.69) more likely to have an unlisted number (29.7\% of unlisted versus $11.4 \%$ of listed) than those who had resided in Australia for 10 or more years $(n=830 ; 70.3 \%$ of unlisted versus $88.6 \%$ of listed). 
TABLE 1: Odds ratios (OR) and 95\% confidence intervals (CI) for association between demographic characteristics and having an unlisted telephone number.

\begin{tabular}{|c|c|c|c|c|c|c|c|c|}
\hline \multirow{2}{*}{$\begin{array}{l}\text { Demographic } \\
\text { characteristic }\end{array}$} & \multicolumn{2}{|c|}{ Unlisted } & \multicolumn{2}{|c|}{ Listed } & \multicolumn{2}{|c|}{ Unadjusted } & \multicolumn{2}{|c|}{ Adjusted $^{\mathrm{a}}$} \\
\hline & $n$ & $\%$ & $n$ & $\%$ & OR & $95 \% \mathrm{CI}$ & OR & $95 \% \mathrm{CI}$ \\
\hline \multicolumn{9}{|l|}{ Gender } \\
\hline Male & 458 & 56.9 & 2165 & 54.5 & 1.00 & & 1.00 & \\
\hline Female & 347 & 43.1 & 1807 & 45.5 & 0.91 & $0.78-1.06$ & 0.89 & $0.76-1.04$ \\
\hline \multicolumn{9}{|l|}{ Age } \\
\hline $18-34$ & 179 & 22.4 & 508 & 12.9 & 1.59 & $1.30-1.94$ & 1.61 & $1.31-1.97$ \\
\hline $35-50$ & 408 & 51.1 & 1840 & 46.7 & 1.00 & & 1.00 & \\
\hline $51-65$ & 211 & 26.4 & 1589 & 40.4 & 0.60 & $0.50-0.72$ & 0.62 & $0.52-0.74$ \\
\hline \multicolumn{9}{|l|}{ Country of birth } \\
\hline Australia & 593 & 73.8 & 3194 & 80.5 & 1.00 & & 1.00 & \\
\hline Other & 210 & 26.2 & 774 & 19.5 & 1.46 & $1.23-1.74$ & 1.38 & $1.14-1.68$ \\
\hline \multicolumn{9}{|l|}{ Main language } \\
\hline English & 780 & 97.0 & 3902 & 98.2 & 1.00 & & 1.00 & \\
\hline Other & 24 & 3.0 & 70 & 1.8 & 1.72 & $1.07-2.74$ & 1.00 & $0.60-1.66$ \\
\hline \multicolumn{9}{|l|}{ Highest education } \\
\hline High school or less & 286 & 35.6 & 1473 & 37.2 & 1.00 & & 1.00 & \\
\hline Trade certificate/diploma & 195 & 24.2 & 1126 & 28.5 & 0.89 & $0.73-1.09$ & 0.91 & $0.75-1.12$ \\
\hline Bachelor degree or higher & 323 & 40.2 & 1358 & 34.3 & 1.23 & $1.03-1.46$ & 1.17 & $0.97-1.41$ \\
\hline \multicolumn{9}{|l|}{ Socioeconomic status ${ }^{\mathrm{b}}$} \\
\hline Highest quintile & 228 & 28.3 & 1102 & 27.7 & 1.00 & & 1.00 & \\
\hline 4th quintile & 207 & 25.7 & 998 & 25.1 & 1.00 & $0.82-1.23$ & 1.05 & $0.85-1.31$ \\
\hline 3rd quintile & 165 & 20.5 & 798 & 20.1 & 1.00 & $0.80-1.25$ & 1.22 & $0.96-1.55$ \\
\hline 2nd quintile & 110 & 13.7 & 698 & 17.6 & 0.76 & $0.60-0.97$ & 1.00 & $0.76-1.30$ \\
\hline Lowest quintile & 95 & 11.8 & 376 & 9.5 & 1.22 & $0.94-1.59$ & 1.44 & $1.07-1.94$ \\
\hline \multicolumn{9}{|l|}{ Remoteness $^{\mathrm{c}}$} \\
\hline Major city & 553 & 68.7 & 2371 & 59.7 & 1.00 & & 1.00 & \\
\hline Inner regional & 173 & 21.5 & 1127 & 28.4 & 0.66 & $0.55-0.79$ & 0.68 & $0.56-0.84$ \\
\hline Outer regional & 69 & 8.6 & 409 & 10.3 & 0.72 & $0.55-0.95$ & 0.64 & $0.47-0.87$ \\
\hline Remote/very remote & 10 & 1.2 & 65 & 1.6 & 0.66 & $0.34-1.29$ & 0.56 & $0.27-1.17$ \\
\hline \multicolumn{9}{|l|}{ State } \\
\hline Victoria & 173 & 21.5 & 677 & 17.1 & 1.00 & & 1.00 & \\
\hline New South Wales & 189 & 23.5 & 1002 & 25.2 & 0.74 & $0.59-0.93$ & 0.72 & $0.57-0.92$ \\
\hline Queensland & 93 & 11.5 & 437 & 11.0 & 0.83 & $0.63-1.10$ & 0.75 & $0.56-1.00$ \\
\hline Western Australia & 241 & 29.9 & 1430 & 36.0 & 0.66 & $0.53-0.82$ & 0.63 & $0.50-0.78$ \\
\hline South Australia & 27 & 3.4 & 83 & 2.1 & 1.27 & $0.80-2.03$ & 1.01 & $0.62-1.65$ \\
\hline Australian Capital Territory & 17 & 2.1 & 72 & 1.8 & 0.92 & $0.53-1.61$ & 1.08 & $0.60-1.93$ \\
\hline Tasmania & 11 & 1.4 & 41 & 1.0 & 1.05 & $0.53-2.09$ & 1.61 & $0.76-3.43$ \\
\hline Northern Territory & 54 & 6.7 & 230 & 5.8 & 0.92 & $0.65-1.29$ & 0.80 & $0.56-1.14$ \\
\hline
\end{tabular}

${ }^{a}$ Mutually adjusted analysis.

${ }^{\mathrm{b}}$ Based on Socio-Economic Indexes For Areas Index of Relative Socio-Economic Disadvantage (SEIFA IRSD); highest quintile comprises least disadvantaged.

${ }^{c}$ Based on Accessibility/Remoteness Index of Australia (ARIA+).

\section{Discussion}

As traditional directory-based telephone surveys are likely to exclude those whose telephone numbers are not listed in the White Pages directories, it is important to understand how these individuals may differ from those with listed numbers. This study investigated the demographic differences between listed and unlisted households in the Australian working population, updating previous research conducted in two
Australian states. In addition, this study further explored differences in terms of educational attainment, as past research has produced inconsistent findings in this regard.

In line with previous research, age and country of birth were significantly associated with having an unlisted telephone number $[1,6,8,10]$. Specifically, respondents aged between 18 and 34 were more likely than those aged between 35 and 50 to have an unlisted number, while those aged over 50 were significantly less likely to live in an unlisted 
household. In addition, foreign-born respondents were 1.4 times more likely than Australian-born respondents to live in a household which was not listed in the White Pages. Education was not significantly associated with having an unlisted number. This is consistent with previous research conducted in New South Wales [10] but not with a South Australian study which found that those with an unlisted number were more likely to have attained a higher educational level [1].

After adjusting for all other demographic variables, living in a low socioeconomic status area was also found to be significantly associated with having an unlisted telephone number, in line with past research [1]. Similarly, living in a major city was significantly associated with having an unlisted number, consistent with previous studies [1,9]. Differences in the proportion of unlisted households were also found between the states, with those in New South Wales, Queensland, and Western Australia more likely to have an unlisted number than those in Victoria. Previous Australian studies have not looked at differences between states in terms of their listed status, although studies in the US have found differences in the proportion of unlisted households across districts [6].

The results of this study show that an unrepresentative sample may be obtained if recruitment is limited to those with listed telephone numbers only. Young people are less likely to have a listed telephone number and young men in particular are a subset of the population from whom recruitment and participation in research is already difficult [16]. Similarly, people born outside of Australia, and particularly those arriving in recent years, are less likely to have a listed telephone number. Australia is a nation of migrants with one in four being born overseas $[17,18]$. People from ethnic minority groups are as likely to participate in scientific research as those from majority populations $[19,20]$, and therefore a sampling frame as wide as possible should be utilised.

The current results may be biased due to the potential nonrepresentativeness of the original sample, as well as those who agreed to participate. This is a limitation of using commercial samples, as the original sampling frame is somewhat unknown. However, the sample does reflect the distribution of listed and unlisted households in the general population, with a similar proportion of unlisted households found in this study (18\%) as has been found in past research [10]. In addition, the cooperation rate observed in this study $(72.8 \%)$ is very acceptable for a telephone survey, particularly in the context of declining response rates in epidemiological studies as a whole [21]. Further, this study aimed only to gain a representative sample of the working population, and so, generalisation of these results to the wider population may be inappropriate. This study may also be limited by the small numbers observed in some remoteness and state groups, meaning that results pertaining to these variables may need to be interpreted with caution. Additionally, the socioeconomic status measure we used was an ecological measure, rather than individual level, and this may be a potential source of bias in our results [22].

\section{Conclusions}

The current study has shown important demographic differences between listed and unlisted households, supporting previous state-based findings on a national level. However, differences between states have also been found, indicating that these previous state-based studies may not be entirely generalisable to the Australian population as a whole. In conclusion, our results suggest that care should be taken when generalising findings from studies which exclude unlisted households, especially where the variables under study are thought to be associated with demographic variables such as age and country of birth [10].

\section{Conflict of Interests}

The authors declare that there is no conflict of interests regarding the publication of this paper.

\section{Acknowledgments}

This study was funded by the National Health and Medical Research Council (NHMRC), Project Grant no. 1003563, and the Cancer Council Western Australia. Professor Lin Fritschi is supported by NHMRC and the Cancer Council Western Australia fellowships. The authors acknowledge the coinvestigators in this study: Associate Professor Deborah Glass, Associate Professor Tim Driscoll, and Dr. Geza Benke. The authors also thank Vicki Graham and Theresa Wilkes at the Survey Research Centre, Edith Cowan University, Western Australia, for their assistance in the data collection for this paper.

\section{References}

[1] E. D. Grande and A. W. Taylor, "Sampling and coverage issues of telephone surveys used for collecting health information in Australia: results from a face-to-face survey from 1999 to 2008," BMC Medical Research Methodology, vol. 10, article 77, 2010.

[2] C. Rissel, L. Jorm, and J. Ward, "Representativeness of three survey methods in ethnic health research," Asia-Pacific Journal of Public Health, vol. 10, no. 2, pp. 100-105, 1998.

[3] J. J. Hox and E. D. De Leeuw, "A comparison of nonresponse in mail, telephone, and face-to-face surveys-applying multilevel modeling to meta-analysis," Quality \& Quantity, vol. 28, no. 4, pp. 329-344, 1994.

[4] Australian Communications and Media Authority, "Communications report 2010-11," Tech. Rep., Commonwealth of Australia, Melbourne, Australia, 2011.

[5] Australian Bureau of Statistics, Household Telephone Connections: Queensland, Australian Bureau of Statistics, Canberra, Australia, 2004.

[6] S. R. Orden, A. R. Dyer, K. Liu et al., "Random digit dialing in Chicago CARDIA: comparison of individuals with unlisted and listed telephone numbers," American Journal of Epidemiology, vol. 135, no. 6, pp. 697-709, 1992.

[7] A. W. Taylor, D. H. Wilson, and M. Wakefield, "Differences in health estimates using telephone and door-to-door survey methods-a hypothetical exercise," Australian and New Zealand Journal of Public Health, vol. 22, no. 2, pp. 223-226, 1998. 
[8] E. Dal Grande, A. Taylor, and D. Wilson, "Is there a difference in health estimates between people with listed and unlisted telephone numbers?" Australian and New Zealand Journal of Public Health, vol. 29, no. 5, pp. 448-456, 2005.

[9] E. von der Lippe, P. Schmich, and C. Lange, "Advance letters as a way of reducing non-response in a National Health Telephone Survey: differences between listed and unlisted numbers," Survey Research Methods, vol. 5, no. 3, pp. 103-116, 2011.

[10] W. Smith, P. Mitchell, K. Attebo, and S. Leeder, "Selection bias from sampling frames: telephone directory and electoral roll compared with door-to-door population census: results from the Blue Mountains Eye Study," Australian and New Zealand Journal of Public Health, vol. 21, no. 2, pp. 127-133, 1997.

[11] D. H. Wilson, G. J. Starr, A. W. Taylor, and E. Dal Grande, "Random digit dialling and electronic white pages samples compared: demographic profiles and health estimates," Australian and New Zealand Journal of Public Health, vol. 23, no. 6, pp. 627-633, 1999.

[12] Australian Bureau of Statistics, Labour Force Australia, Australian Bureau of Statistics, Canberra, Australia, 2011.

[13] Australian Bureau of Statistics, Socio-Economic Indexes For Areas 2006, Australian Bureau of Statistics, Canberra, Australia, 2008.

[14] Australian Bureau of Statistics, Australian Standard Geographical Classification, Australian Bureau of Statistics, Canberra, Australia, 2011.

[15] StataCorp, "Stata Statistical Software: release 12," Tech. Rep., StataCorp LP, Lakeway, Tex, USA, 2011.

[16] Australian Bureau of Statistics, "Census of population and housing: details of undercount 2011," Tech. Rep., Australian Bureau of Statistics, Canberra, Australia, 2012.

[17] S.-E. Khoo, "Ethnic disparities in social and economic wellbeing of the immigrant aged in Australia," Journal of Population Research, vol. 29, no. 2, pp. 119-140, 2012.

[18] "Fact sheet 4-more than 60 years of post-war migration," Department of Immigration and Citizenship, 2009, http://www.immi.gov.au/media/fact-sheets/04fifty.htm.

[19] D. Wendler, R. Kington, J. Madans et al., "Are racial and ethnic minorities less willing to participate in health research?" PLoS Medicine, vol. 3, no. 2, pp. 201-210, 2006.

[20] S. Mason, M. Hussain-Gambles, B. Leese, K. Atkin, and J. Brown, "Representation of South Asian people in randomised clinical trials: analysis of trials' data," British Medical Journal, vol. 326, no. 7401, pp. 1244-1245, 2003.

[21] S. Galea and M. Tracy, "Participation Rates in Epidemiologic Studies," Annals of Epidemiology, vol. 17, no. 9, pp. 643-653, 2007.

[22] H. Gravelle, "How much of the relation between population mortality and unequal distribution of income is a statistical artefact?" British Medical Journal, vol. 316, no. 7128, pp. 382385, 1998. 


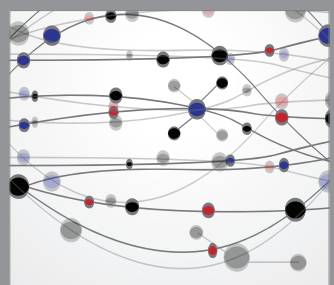

The Scientific World Journal
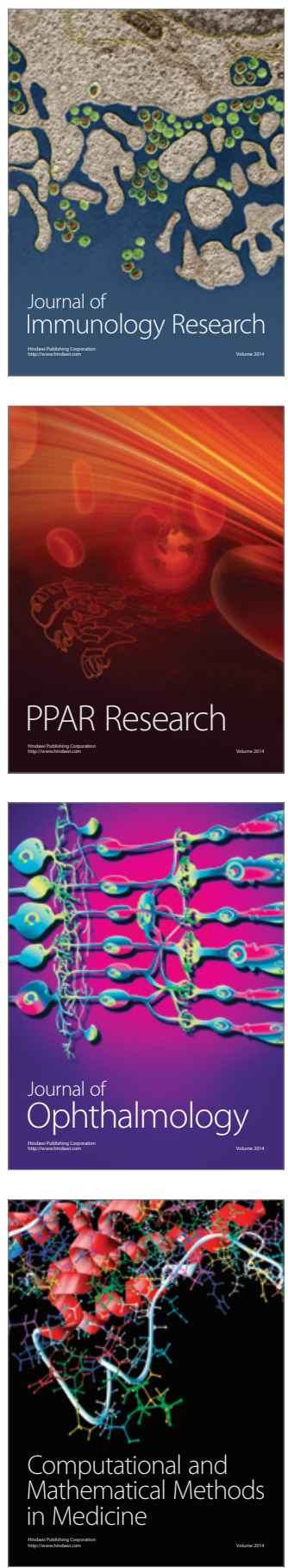

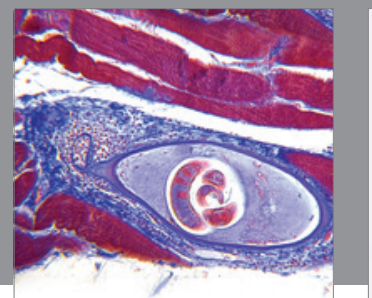

Gastroenterology

Research and Practice
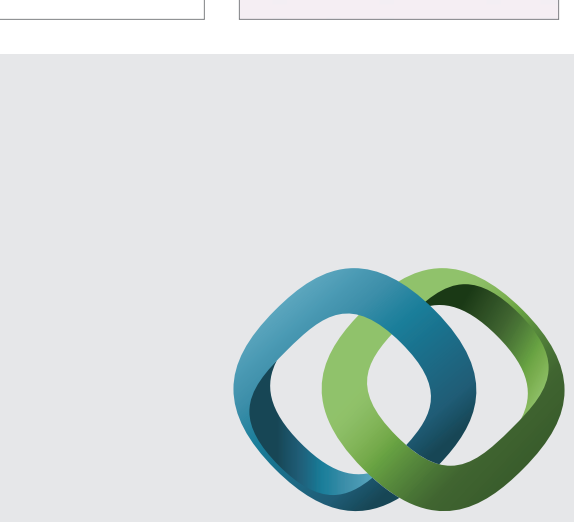

\section{Hindawi}

Submit your manuscripts at

http://www.hindawi.com
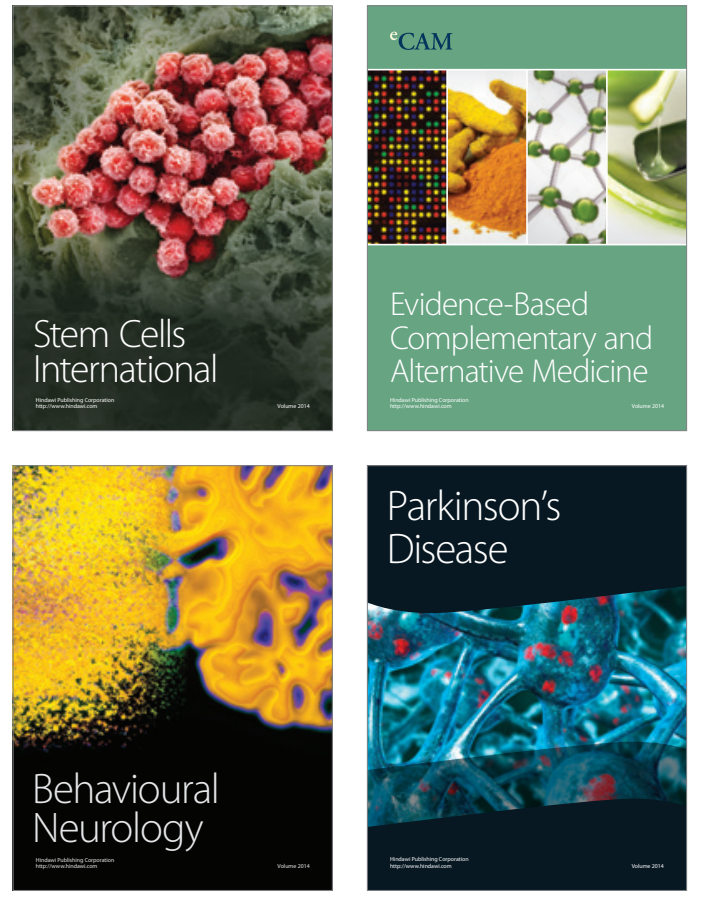
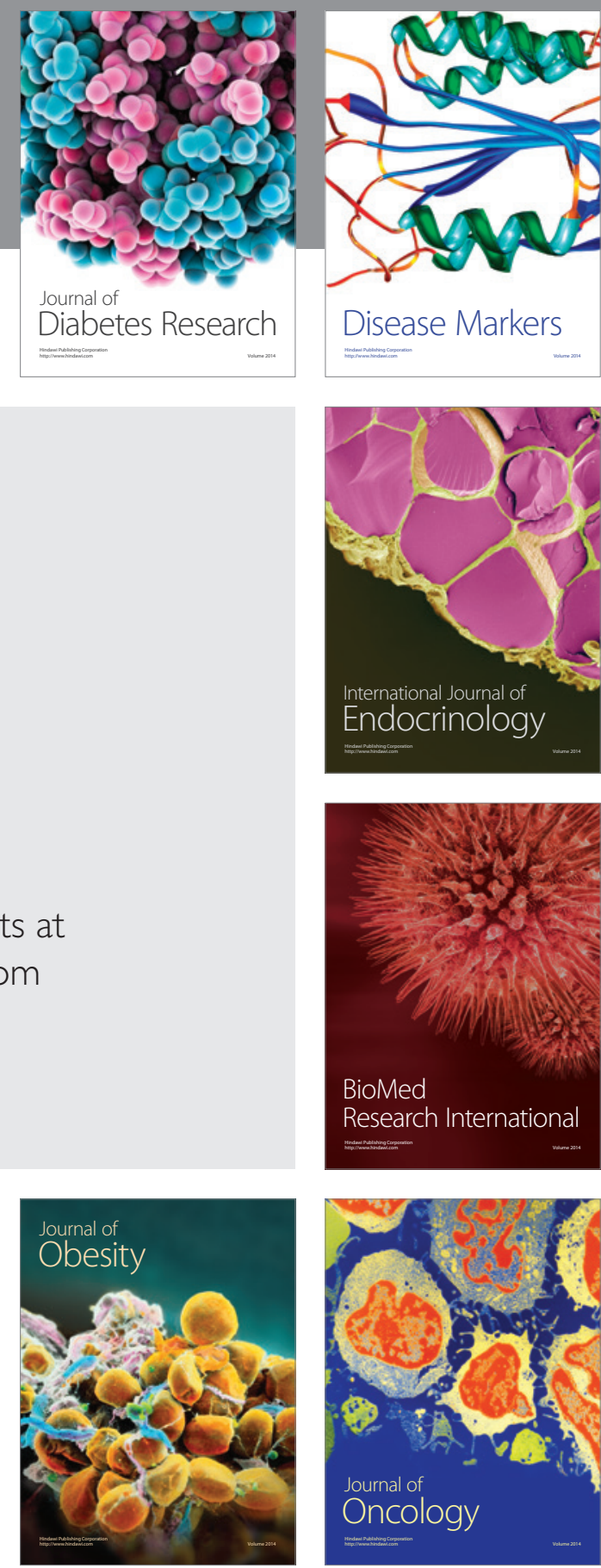

Disease Markers
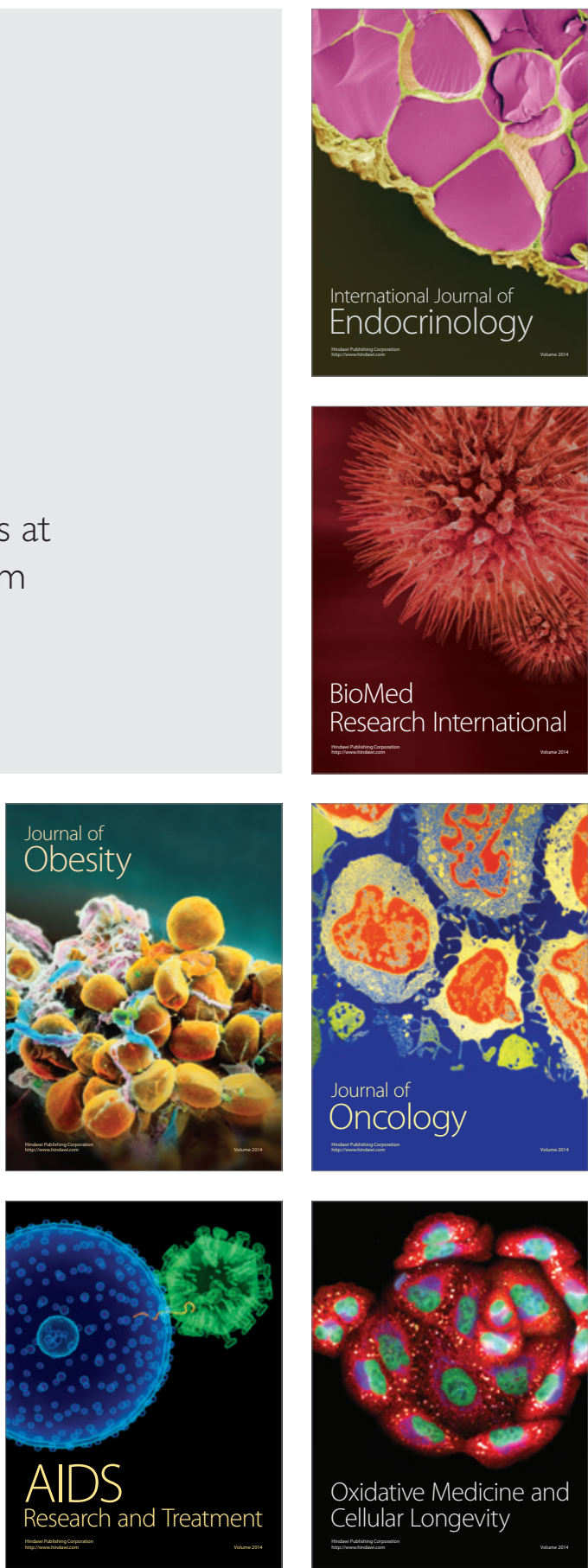